KubleR, George: La obra del Escorial. Versión española de Fernando Villaverde, Madrid, Alianza Editorial, 1983.

Llaguno y Amirola, Eugenio: Noticias de los arquitectos y arquitectura de España desde su restauración. Ilustradas y acrecentadas con notas, adiciones y documentos por D. Juan Agustín Cean-Bermúdez, I y II, Madrid, Imprenta Real, 1829.

Martín Gonzalez, J. J.: "Noticias varias sobre artistas de la Corte en el siglo Xvi», en Boletín del Seminario de Estudios de Arte y Arqueología, XXXV, Valladolid, Universidad (1971), 225-240.

Menéndez Pelayo, Marcelino: Historia de las Ideas Estéticas en España, II, Santander, Aldus, 1940.

Picatoste y Rodríguez, Felipe: Apuntes para una biblioteca científica española del siglo xVI, Madrid, Manuel Tello, 1891.

Ruiz de Arcaute, Agustín: Juan de Herrera. Arquitecto de Felipe II, Madrid, Espasa Calpe, 1936.

Simons, Edison y Godoy, Roberto: Discurso del Señor Juan de Herrera, aposentador Mayor de S.M., sobre la figura cúbica, Madrid, Editora Nacional, 1976.

Vicente Maroto, María Isabel: «Juan de Herrera, un hombre de ciencia», en Juan de Herrera y su influencia Actas del Simposio. Camargo, 14-17 julio 1992. Fundación Obra Pía Juan de Herrera, Universidad de Cantabria (1993), 79-89.

Wilkinson-Zerner, Catherine: Juan de Herrera. Architect to Philip II of Spain, New Haven and London, Yale University Press, 1993.

\title{
NOTICIAS BIOGRÁFICAS DE UN ESCULTOR DEL SIGLO XVIII: JUAN DE LEÓN
}

Al revisar la bibliografía sobre escultura del siglo xviII no es difícil encontrar citado a Juan de León cuando se mencionan algunas obras escultóricas relevantes de este siglo. Así, una y otra vez, son varios los autores que repiten su intervención en los dos importantes mausoleos reales: el de la reina M. ${ }^{a}$ Bárbara de Braganza (fig. 1 y 3) y en el de su esposo, el rey Fernando VI ${ }^{1}$, ambos en la iglesia del Monasterio de la Visitación de Madrid o Salesas Reales. Si bien no dejamos de reconocer que, por ahora, ambos sepulcros forman parte de su producción escultórica más citada y conocida no se resume únicamente en estas dos obras su labor artística. A Juan de León se le señala también como el encargado por la Junta de Fuentes del Ayuntamiento de Madrid, de labrar las esculturas que adornaban la Fuente de la Villa ${ }^{2}$ (fig. 2), obra que fue proyectada por Saqueti, hoy desaparecida, y que se adornaba con cuatro leones que arrojaban agua por la boca, sobre los que se asentaba un castillo, que sostenía como remate una figura de mujer con traje militar y un estandarte en la mano. Esta ornamentación fue hecha por el escultor en 5 meses -firmó el contrato el 17 de mayo de 1754 y se inauguró el 22 de septiembre del citado año-, haciendo manar vino por sus caños durante 15 minutos en tan señalado día.

Al proseguir revisando su labor artística volvemos a encontrarlo entre el escaso número de escultores españoles que fueron elegidos para intervenir en la decoración de la Capilla del Pala-

1 A. Ponz: Viage de España, pág. 481. Álvarez Quindos, pág. 368. E. Serrano Fatigati: Bol. Soc. Esp. Exc., t. 18, 1910, pág. 70. Polentinos, Conde de: Bol. Soc. Esp. Exc., t. 24, 1916, 281. Ceán: Dicc., t. III, pág. 10. Cruz Bahamonde: Viaje..., t. X, 540. E. Tormo: Las iglesias del antiguo Madrid, 1927. F. Portela Sandoval: La escultura en tiempos de Carlos III, Madrid, 1989. La ornamentación escultórica en la arquitectura de Sabatini en el Catálogo de la Exposición Francisco Sabatini, octubre-diciembre 1993.

2 Polentinos, Conde de: Datos históricos sobre la Casa Ayuntamiento de Madrid, Bol. Soc. Esp. Exc., t. 20, 1912, pág.

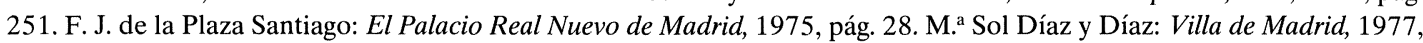
págs. $49,50$. 

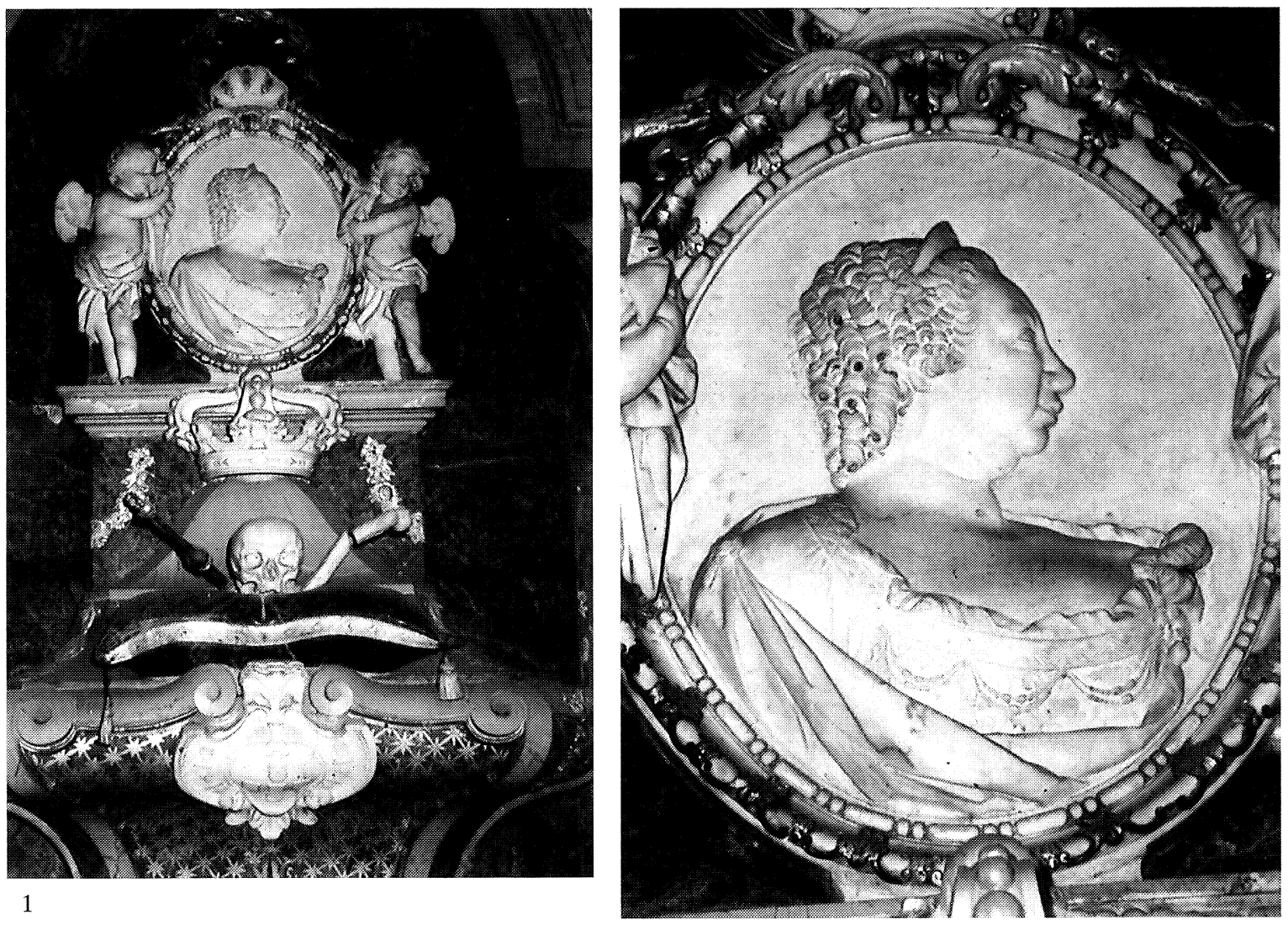

1

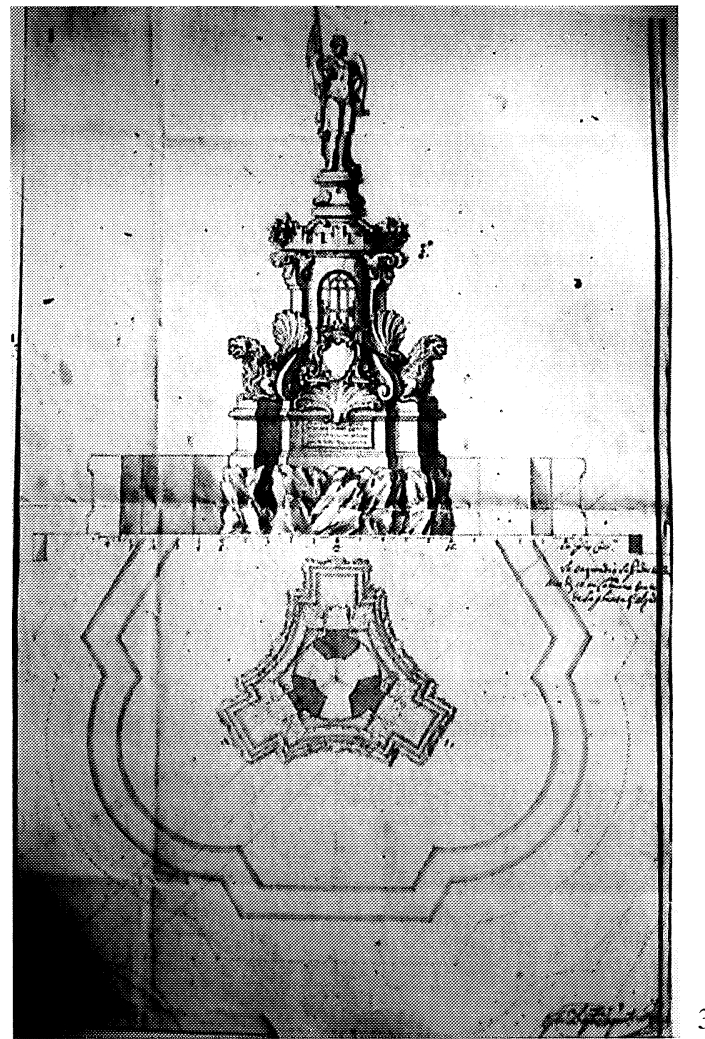

Figs. 1 y 2. Juan de León, Mausoleo de Barbara de Braganza, conjunto y detalle. Madrid, Monasterio de la Visitación. Iglesia.

Fig. 3. Juan Bautista Saqueti, Proyecto de la fuente de la Plaza de la Villa. Madrid, Archivo de la Villa. 
cio Real de Madrid ${ }^{3}$ (fig. 4), al desistir Felipe de Castro, alegando motivos de salud, el continuar la parte de trabajo que allí se le había asignado. La renuncia de Castro obligó a buscarle un sustituto. La obra que debía realizar el escultor gallego se adjudicó: la mitad, al francés Roberto Michel, y la otra mitad la compartieron dos escultores españoles: Manuel Alvarez de la Peña «el griegony Juan de León. Este, pues, fue elegido esta vez compartiendo trabajo junto a los más prestigiosos escultores del siglo xviII en la Corte, Michel y Olivieri y, nuevamente, para desempeñar un trabajo de importancia, como lo era la ornamentación de la capilla del Palacio Real. Para comprender mejor, quizás, lo que supone su selección, conviene no olvidar el gran número de escultores presentes en la Corte, con un prestigio reconocido y deseosos de desempeñar una labor de tal entidad. El que Juan de León fuese el elegido, junto a los dos extranjeros y el español mencionado, puede darnos idea de su reconocidos méritos de escultor.

En esta revisión de su producción artística hay que recordar su participación en la decoración de la Capilla del Pilar de Zaragoza, trabajando en los estucos de su bóveda ${ }^{4}$.

Se cuentan, también, entre sus obras, el haber labrado cuatro esculturas para la balaustrada del Palacio: los reyes Recaredo, Chindasvinto, Isabel la Católica y su esposo el rey D. Fernando. La situación de ellas en la balaustrada era: una en el centro de la fachada hacia la Plaza de Oriente, otra en una de las torres del Palacio, en esta misma fachada y las otras dos hacia Poniente o Campo del Moro.

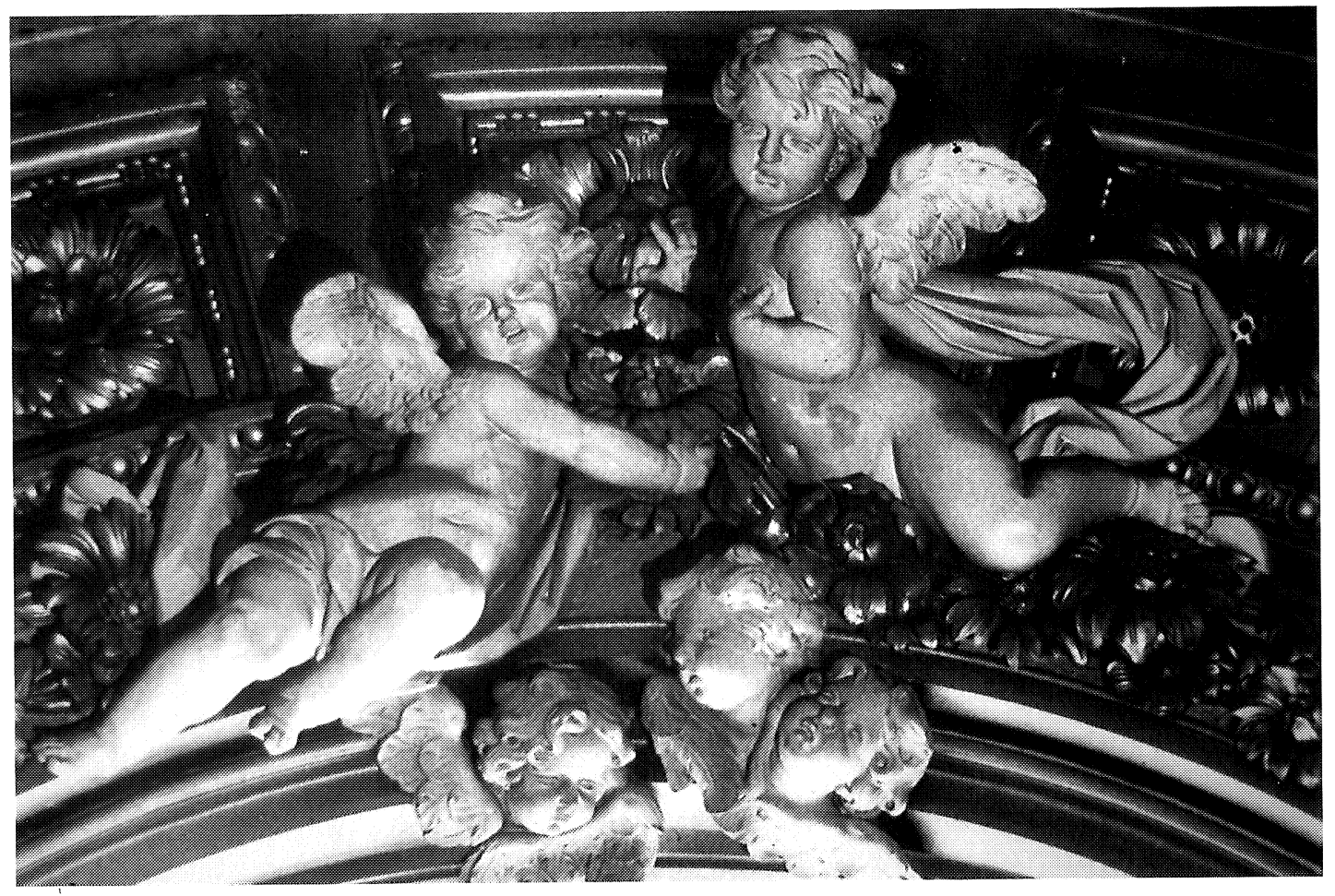

Fig. 4. Juan de León, Angeles querubines. Madrid, Palacio Real: capilla.

Además, Juan de León figura como autor de una de las estatuas que se hicieron para decorar el piso principal del referido Palacio. En estas esculturas no tuvieron oportunidad de trabajar

3 F. J. de la Plaza Santiago: ob. cit., págs. 148, 149. M. L. Tárraga Baldó: G. D. Olivieri y el taller de escultura del Palacio Real, 1992, vol. III, págs. 351-353.

4 A. Ponz: Viage de España, pág. 1303. 
más que unos pocos artífices. Los escultores que se eligieron para labrarlas fueron, exactamente, trece y, según consta, éstos fueron seleccionados entre los que se consideraban eran los mejores que entonces estaban trabajado en el taller real a las órdenes de los dos Directores de escultura del Palacio. Es interesante destacar este hecho, porque nos vuelve a poner de manifiesto el aprecio y consideración que gozaba este artista. Para el piso principal del Palacio esculpió León la estatua del rey Jaime I el Conquistador de Aragón.

Juan de León vuelve a figurar, además, en la lista confeccionada por Felipe de Castro con los nombres de aquellos artífices que él consideraba eran los doce mejores escultores a quienes, como tales, propuso para que se les encargase el labrar los relieves que debían decorar las sobrepuertas de la galería principal del Palacio. A Juan de León se le encomendaron dos de ellos: «El martirio de S. Lorenzo", hoy en la Academia de San Fernando como depósito del Museo del Prado y «El III Concilio de Toledo", relieve inacabado y hoy conservado en los almacenes del referido Museo ${ }^{5}$. El que se le adjudicasen dos, también es bastante significativo, sobre todo si tenemos en cuenta las solicitudes de otros escultores pretendiendo poder labrar alguno de estos relieves y que no llegan a conseguirlo, aún mediando las recomendaciones de altos e importantes mandatarios de la Corte.

A todo lo dicho podemos añadir, como novedad, el que debido a la disparidad de criterios de Olivieri y Castro en la valoración del relieve labrado por el francés Francisco Devoge, se eligió a Juan de León para que junto con Roberto Michel retasasen el citado relieve ${ }^{6}$, lo que demuestra, una vez más, la alta estima en que se le tenía.

Otra de sus obras es la estatua de S. Nicolás para la iglesia de Ntra. Sra de Atocha 7.

A lo expuesto hay que sumar los juicios que han merecido sus trabajos y que conocemos gracias a varios testimonios de archivo que corresponden a artistas contemporáneos de León, entre los que figuran nombres tan prestigiosos como el pintor Giaquinto, los arquitectos Bonavia, Saqueti, Sabatini o los escultores Olivieri y Castro Y no sólo contamos con los juicios de contemporáneos, sino con algunas otras opiniones posteriores, que han seguido reconociendo su valía y enjuiciando elogiosamente su obra. En este sentido he querido recoger algunos testimonios al respecto. Así, el italiano Olivieri, refiriéndose al relieve que esculpió con el tema del Martirio de San Lorenzo, actualmente en la Academia de San Fernando dirá: «...es una de las medallas que me gusta más y tiene mucha obra...." ${ }^{\text {; }}$ Giaquinto al dar su parecer sobre los estucos de la Capilla del Palacio exponía: «...mi recano ancor a me amirazione por quel che appartienne al lavoro di D. Manuel Alvarez e D. Giovanni de Leoni" ' 9 , sin embargo no estaba tan de acuerdo con los de Roberto Michel.

Hemos tenido la suerte de conseguir también la opinión que su trabajo mereció a otro italiano :el arquitecto Bonavía. La noticia nos la facilita el archivo del Palacio. Exactamente, en 1747, con motivo de haberse de encargar la ejecución de unas chimeneas para el Palacio de Aranjuez destinada a las habitaciones de Sus Majestades Bonavia manifiesta que no quería que «...se ejecuten por mano de chapuceros que regularmente suelen ser los que lo hacen más barato..., de las que hasta ahora se han executado las mejores son las de Juan de León, por mal nombre el romo, bien conocido del $\mathrm{Sr}$. Elgueta...» ${ }^{10}$.

\footnotetext{
5 Tárraga Baldo, M. L.: Los relieves.

6 Se trata del relieve "La edición de la Biblia Complutense", hoydesaparecido, que fue tasado por Olivien en 18.000 rs y por Felipe de Castro en 10.000. León junto con los otros escultores lo valoraron en 15.000 rs., Voge recibió finalmente 14.000 rs. por este trabajo A.G.P. Secc. $o b .460$.

7 A. Ponz: ob. cit., pág. 417.

8 A. G. P. Secc. Ob. Leg ${ }^{\circ}$ 4.V. Plaza Santiago: ob. cit. Apéndice Documental, pág. 410.

9 M. C. García Sáseta: Corrado Giaquinto en España. Atti Convegno di Studi su Corrado Giaquinto, Molfeta, 1969, pág. 65.

10 A.G.P. Leg $^{\circ} 367 \mathrm{Ob}$.
} 
De la crítica posterior, y sólo por citar algún otro testimonio al respecto, contamos con la opinión de Ponz. Este, al referirse a la Capilla del Pilar, después de citar a los que participaron en su decoración escribe : Estas obras se repartieron con juicio entre diferentes profesores, como debe hacerse cuando ocurren ocasiones semejantes y tienen mérito los que pueden hacerlas, porque así hay emulación entre ellos y se esmeran por superarse...” ${ }^{11}$. Luis Pulido y Timoteo Díaz señalan que el Cabildo del Pilar pidió a Fernando VI en 1750 que le enviase el más brillante arquitecto, y más adelante añaden al referirse a su ornamentación: «Toda la capilla está adornada con estatuas, medallas y bajorrelieves... en mármoles unos, otros en estuco y algunos en bronce «ejecutados por los más insignes escultores de aquella época» ${ }^{12}$.

Si su prolongada labor siguió recogiendo el aplauso y la admiración de los entendidos, es necesario, tras este breve repaso de su producción, el preguntarse ¿de dónde procedía este escultor que para tan meritorias tareas se eligió? ¿Dónde se formó? Estas interrogaciones nos han llevado a indagar a fin de conocer sus rasgos biográficos, empezando por su origen, detalle que, hasta ahora, constituía una incógnita no desvelada. Ceán ${ }^{13}$ en su Diccionario sólo nos facilita vagas noticias de Juan de León. Prescinde, casi por completo, de referencias biográficas. Ponz ${ }^{14}$ las omite también. Tormo ${ }^{15} \mathrm{y}$ más recientemente Belén Boloqui ${ }^{16}$ aceptan que se han documentado bastantes obras suyas, sin embargo no dejan de reconocer que «... apenas si se saben datos de su vida». Efectivamente, al igual que le sucede a otros muchos escultores del siglo xviII, Juan de León es un artista del que se carece de datos biográficos. Se le cita una y otra vez con referencia a obra representativas de nuestra escultura cortesana, según hemos expuesto, pero nada se aporta sobre su vida.

F. J. de la Plaza ${ }^{17}$ planteó la posibilidad de su origen italiano, basándose en el escrito de Giaquinto, anteriormente reproducido, y en el que el pintor italianiza su nombre. Para Manuel V. Aramburu ${ }^{18}$ era aragonés y de la misma opinión será también Belén Boloqui, aunque hasta la fecha no se habían aportado pruebas que así lo atestiguasen.

Las investigaciones que en el campo de la escultura vengo realizando me han proporcionado la posibilidad de desvelar este y otros detalles de su biografía: en primer lugar su origen, así como otras interesantes noticias sobre su vida o sobre algunos rasgos de su personalidad humana. Si se ha llegado a sugerir la posibilidad de un origen italiano, quizá haya que pensar que tal hipótesis no ha estado únicamente propiciada por la grafía con que se ha transcrito su apellido, sino que a ello ha podido contribuir también el que una gran parte de sus obras están realizadas en estrecha relación con artistas italianos, circunstancia que, evidentemente, hemos podido constatar al exponer su trayectoria artística, así como al recoger los juicios de valor que han merecido sus trabajos y que, una vez más, esta preferencia hacia él de los artistas italianos en la corte, corrobora la calidad de su arte.

Cuando se recurre a consultar algunos diccionarios de artistas con el deseo de encontrar algún datos que nos descubran la parte humana del escultor nos encontramos con que aparecen recogidos varios de este apellido, pero al llegar a Juan de León, escultor y estucador, enmudecen, y comienzan dejando un claro para situar la fecha de su nacimiento; todo lo más que se atreven es a aportar el año 1800 como el de su fallecimiento, noticia que se ha venido repitiendo, sin duda, teniendo en cuenta a Ceán, quien asegura que Juan de León falleció en Madrid

\footnotetext{
11 A. Ponz: ob. cit., pág. 1303.

12 L. Pulido López y T. Díaz Galdós: Biografía de D. Ventura Rodríguez Tizón, Madrid, 1898, pág. 58.

13 A. Ceán: Diccionario..., vol. III, pág. 10.

14 Ponz: ob. cit.

15 E. Tormo: Las iglesias del Antiquo Madrid, 1927.

16 Belén Boloqui: Escultura zaragozana en la época de los Ramírez, 1710-1780. Ministerio de Cultura. Ed. Anel. Granada 1983, vol. I, pág. 177.

17 F. J. de la Plaza: ob. cit., pág. 149.

18 Aramburu de la Cruz, M.V: Historia Chronologica de la Santa Capilla de Nuestra Señora del Pilar... Zaragoza 1766, pág. 104.
} 
«poco tiempo hace» y, como el Diccionario de Ceán corresponde al año de 1800, no ha habido inconveniente en tomar esta fecha como referencia a su defunción. Este único dato biográfico que, a veces, se incorpora a su nombre, no puede ser aceptado como más adelante se verá.

Hoy, la documentación de que disponemos nos permite asegurar que Juan de León, el escultor del siglo XVIII, no era italiano, sino aragonés. Nació en un pueblecito de la provincia de Teruel, concretamente, en Bañón, el día 11 de junio de 1712 y allí, en su iglesia parroquial de San Juan Bautista fue bautizado al día siguiente, 11 de junio, por el cura de la parroquia, D. José Mañes, imponiéndosele el nombre de Juan Bernabé León "primero de este nombre». Sus padres fueron Domingo León y Juana Aranda; su padrino, Juan Juste, boticario ${ }^{19}$. El escultor firmaría a lo largo de su vida con Juan de León, suprimiendo su segundo nombre. Ni que decir tiene que la elección de tal nombre tendría que ver con el patrono de la iglesia de donde era oriundo y fue bautizado y hasta con su padrino en la ceremonia.

Hasta ahora ninguna otra noticia he conseguido de su niñez. Respecto a su formación, me atrevó a sugerir que tuvo lugar en la ciudad de Zaragoza, pero sin datos documentales hasta el momento.

Su presencia en Madrid se detecta en fecha bastante temprana,exactamente, en 1743, año en el que el artista contrae matrimonio.La ceremonia tuvo lugar el 25 de octubre, en la Sacristía de la iglesia de San Ginés ${ }^{20}$, cuando el artista contaba treinta y un año, es decir, era un hombre más bien maduro. Esta edad hace pensar que podría tratarse de un segundo matrimonio; sin embargo, en el acta matrimonial no se refleja esta circunstancia, que por otra parte era usual, entonces, hacerlo constar.

Juan de León casó, pues, en Madrid con Paula de Mella, natural del Puerto de Santa María, Obispado de Cádiz, hija de Nicolás de Mella y Mariana Valdivieso. Le fueron dispensadas las tres amonestaciones, siendo testigos D. Bartolomé Lardier, D. Francisco Botto y D. Agustín Carreyra, "todos presbíteros", dato que nos llama la atención. ¿Carencia de familiares cercanos? ¿Se quiere un acto extremadamente íntimo?

Algunos años más tarde, concretamente, en 1748, nuevas noticias de archivo nos descubren que «...D. Juan De León Maestro de Escultor vive en la calle del Lobo a la entrada en la peluquería. Madrid" ${ }^{21}$. Esta calle se corresponde en la actualidad con la de Echegaray y pertenecía a la parroquia de San Sebastián.

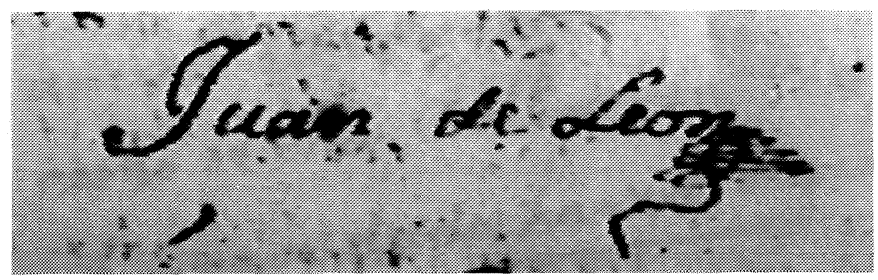

Fig. 5. Firma de Juan de León.

De esta unión matrimonial el escultor tuvo, al menos, un hijo cuya partida de Bautismo se conserva en la iglesia de San Sebastián de Madrid. Nació el 27 de enero de 1748 y al ser bautizado se le impusieron los nombres de: «Juan Julián Miguel». El acto del bautismo tuvo lugar el 30 de enero y es interesante señalar que figura como su «Padrino «D.a Rosa Ballerna, la mujer del escultor Roberto Michel ${ }^{22}$, con quien, sin duda, le unía relaciones profesionales y de amistad.

\footnotetext{
19 Archivo Histórico Diocesano de Teruel. Parroquia de Bañón, t. II de los QUINQUE LIBRI Bautismos, fol. 145 $\mathrm{v}^{\mathrm{o}}$. Quiero manifestar mi agradecimiento a D. Pedro Hernández, Director del Archivo Histórico Diocesano de Teruel quien amablemente atendió mi petición haciéndome llegar esta partida de bautismo.

20 A. Parroquial de San Ginés, Madrid, Lib. 14 de Matrimonios, fol. 28.

21 A.G.P. Secc. Aranjuez. Ca 14.180.

22 A. Parroquial San Sebastián, Madrid, Libro 33 de Bautismos, fol. 376 vo.
} 
Algunos rasgos de su personalidad creemos descubrirlos a través del escrito ya citado de Bonavía y de actitudes que mantiene el propio escultor en relación con la ejecución de varias de sus obras.

En el primer caso Bonavía, al referirse a Juan de León, después de valorar positivamente su labor, añade: "por mal nombre el romo.... frase que se presta a variadas interpretaciones: ¿era Juan de León físicamente de nariz pequeña y achatada?, ¿ era algo bruto como persona?, o más bien ¿en su forma de ser había actitudes que se han venido considerando como característica de los aragoneses?

$\mathrm{Si}$ analizamos sus comportamientos en el trascurso de la ejecución de algunos de sus encargos, observamos cierta informalidad inconstancia, o quizá irresponsabilidad. Estas apreciaciones se apoyan en uno de los escritos hallados y que está fechado en el Buen Retiro el 12 de diciembre de 1748, firmado por el Ministro de Estado José de Carvajal y Lancaster. El escrito está dirigido al Intendente del Palacio, Baltasar de Elgueta, y su contenido dice textualmente: «Haga V. S. buscar al Estucador D. Juan de León, y decirle que dentro de veinte y cuatro horas se presente en Aranjuez a continuar la obra de su cargo, y no salga del Sitio hasta dejarla fenecida: y si pasado este término no se hubiere presentado, hágale V. S. llevar de hecho, y entregarle al Gobernador de aquel Sitio. Dios gde...» ${ }^{23}$. Al margen de esta orden una nota nos informa: «Resultó estar en Aranjuez y se avisó remitiendo la carta que escribió a su mujer». A juzgar por los términos de la orden el escultor aragonés había abandonado el trabajo que realizaba en el Palacio de este Real Sitio, faltando a la obligación que había contraído; al menos, no presentándose a trabajar, según parece desprenderse de la orden de búsqueda dada y firmada por el propio Carvajal y Lancaster. Como quiera que es sabido que León en el Sepulcro de Fernando VI estuvo encargado de su ejecución , firmó el contrato y no llegó a concluirlo, sino que fue realizado por Francisco Gutiérrez, este hecho supondría uno más de sus incumplimientos.A ello podemos añadir algunos otros trabajos inacabados del artista: uno de los relieves para la Galería principal del Palacio representando el "Concilio III de Toledo", que fue recogido, al suspenderse esta ornamentación en el estado que hoy lo conserva el Museo del Prado y según he dado a conocer, aunque se ha venido citando a Juan de León como autor del mismo, no fue labrado por él, pues se lo entregó al escultor, Francisco Matías del Otero, para que lo hiciese. Otero reclamará, tiempo después de haberse recogido el mencionado relieve, la cantidad que se le adeudaba y había percibido León por esta obra, alegando que él había sido quien había elaborado el modelo y desbastado el relieve.

Esta aparente informalidad que nos descubre la documentación hallada, puede estar justificada por los excesivos encargos que el artista aragonés tenía y, casi todos ellos, con plazos fijos para su conclusión. En el caso del Sepulcro de Fernando VI se viene argumentado que abandonó la obra por no poderla realizar en el precio en que él se había comprometido a hacerla.

La diversidad de artistas con idéntico nombre y apellido al de este artista aragonés se suceden a lo largo de varios siglos y aún dentro del xviII, lo cual obliga a ser cauto en las investigaciones sobre este escultor.

Así, hemos comprobado que el 6 de junio de 1754 aparece un «Juan de León, discípulo de la Academia ha presentado varios dibujos, pidió se le permitiese pasar a la sala del modelo vivo. Vistos los dibujos y en ellos la habilidad y adelantamiento del Pretendiente condescendió la Junta a su instancia» ${ }^{24}$. Lógicamente este Juan de León no puede ser el escultor aragonés sino un muchacho en formación, que más bien podríamos identificar con algún hijo del escultor aragonés, pero, por ahora, carecemos de aquellos datos que así permitan afirmarlo. La única partida de bautismo hallada, tanto por los años de este discípulo y las fechas no puede tratarse de un hijo de Juan de León y sí, muy posiblemente con Juan Felipe José de León, natural de Mons, en

\footnotetext{
23 A.G.P. Secc. Ob. Leg $^{\circ} 367$.

24 A. Academia de S. Fernando. Actas. Junta Ordinaria de 6 de junio de 1754.
} 
Flandes y vecino de Madrid, matriculado el 8 de marzo en la Academia y que Pardo Canalís recoge en su publicación de los Registros de Matrículas de la Academia ${ }^{25}$.

También se hace necesario precisar que en el trabajo de Matías Fernández García sobre «Algunos Pintores y escultores que fueron feligreses de la Parroquia madrileña de San Sebastián», figura, entre ellos, la partida de defunción del «escultor Juan de León», pero nada tiene que ver con el escultor aragonés. En el citado estudio se dice tenía al morir, como 62 años en 1797, pero únicamente podemos en principio admitir que se tratase del escultor que con idéntico nombre y apellido hemos anteriormente citado solicitando en la Academia pasar a otro tipo de enseñanza 26.

El escultor y estucador aragonés Juan de León murió en Madrid el 20 de mayo de 1767. Según consta en su partida de defunción, cuando acontece el fallecimiento, estaba casado entonces con Nicolasa Beque, así, pues, el escultor había contraído un segundo matrimonio. En ese año el artista aragonés vivía en la calle de San Carlos y fue enterrado en la iglesia de San Sebastián de Madrid ${ }^{27}$.

Previamente, el día 19 de mayo de ese mismo mes y año, el escultor hizo una Declaración de Pobre ante el escribano Pedro Alvarez. En ella declara ser natural de Bañón, Arzobispado de Zaragoza e hijo legítimo de Domingo de León y Juana de Aranda, ya difuntos. Se encuentra enfermo, pero en su sano juicio y declara «ser pobre de solemnidad, y no tener bienes de que poder disponer por lo que suplica al Señor Cura o su teniente de la Iglesia parroquial de S. Sebastián de esta Corte de adonde es parroquiano... que al tiempo que fallezca le manden enterrar de limosna y hagan por su alma los sufragios que acostumbran con los demás sus feligreses.

Y por si en algún tiempo le tocasen y perteneciesen algunos bienes, dentro o fuera de esta Corte deja e instituye por su única y universal heredera en todos ellos... a Nicolasa Beque, su mujer respecto de no tener herederos forzosos, y la pide le encomiende a Dios...

Son testigos Juan Francisco de la Cavallería, D. Miguel de Olites, y la Caballería y D. Miguel Angel residentes en esta Corte.

Curiosamente esta segunda mujer del escultor contraerá matrimonio, al quedarse viuda, transcurrido algo más de un año, con exactitud el 7 de octubre de 1768, pero, previamente, hace escritura de la dote que aporta al nuevo matrimonio y al hacerse la carta de dote y recibo de pago descubrimos nuevos detalles tanto sobre su identidad como de algunos bienes que con seguridad heredó de su anterior marido, el escultor Juan de León.

Ella que iba a contraer nuevo matrimonio con un viudo se declara natural de la ciudad de Toledo e hija de Manuel Beque e Isabel Martín. En la relación de sus bienes, la mayoría ropas, nos llama poderosamente la atención en primer lugar «Un San Juan de Talla con peana que se tasó en setenta y cinco reales, pero sobre todo la pieza más importante de su herencia y mejor valorada fue un caballo de talla, grande, tasado en mil y quinientos reales.

Se añade en la dote «Doce yerros para trabajos en talla, un mortero de mármol, y entre las piezas de valor algo que no podía faltar en la casa de un aragonés, «Una imagen de la Virgen del Pilar».

Como no doy por zanjada esta investigación y tengo previsto poder dar a conocer nuevas obras de este artista aragonés e incluso ampliar y precisar algunas de las más notables y conocidas, conservo la esperanza de poder también aportar nuevos datos sobre su vida o, al menos, haber facilitado el camino para que otros investigadores pueda completar la biografía de tan excelente escultor.

M. ${ }^{a}$ Luisa TARRAGA Dpto. H. ${ }^{a}$ del Arte del CSIC

25 Pardo Canalís E. Los registros de Matrículas de la Academia de S. Fernando de 1752 a1815 C.S.I.C. Diego Velazquez, Madrid 1967, pág. 60.

${ }^{26}$ Matías Fernández García: Algunos Pintores y Escultores que fueron feligreses de la Parroquia madrileña de S. Sebastián. An. del Ins. Estudios Madrileños, 1982, pág. 82. La partida se halla en el Lib. 38 de Difuntos, fol. 157.

27 A. Parroquial San Sebastián, Madrid, Libro 30 de Difuntos, fol. $292 v^{\circ}$. 